\title{
Deconstructing mammalian reproduction: using knockouts to define fertility pathways
}

\author{
Angshumoy Roy ${ }^{1,2}$ and Martin M Matzuk ${ }^{1,2,3}$ \\ Departments of ${ }^{1}$ Pathology, ${ }^{2}$ Molecular and Human Genetics and ${ }^{3}$ Molecular and Cellular Biology, Baylor College \\ of Medicine, One Baylor Plaza, Houston, TX 77030, USA
}

Correspondence should be addressed to Martin M Matzuk at the Department of Pathology, Baylor College of Medicine, One Baylor Plaza, Houston, TX 77030, USA; Email: mmatzuk@bcm.tmc.edu

\begin{abstract}
Reproduction is the sine qua non for the propagation of species and continuation of life. It is a complex biological process that is regulated by multiple factors during the reproductive life of an organism. Over the past decade, the molecular mechanisms regulating reproduction in mammals have been rapidly unraveled by the study of a vast number of mouse gene knockouts with impaired fertility. The use of reverse genetics to generate null mutants in mice through targeted disruption of specific genes has enabled researchers to identify essential regulators of spermatogenesis and oogenesis in vivo and model human disorders affecting reproduction. This review focuses on the merits, utility, and the variations of the knockout technology in studies of reproduction in mammals.

Reproduction (2006) $131207-219$
\end{abstract}

\section{Introduction}

Living forms are defined by their ability to reproduce. Although different organisms produce progeny using diverse methods (asexual and sexual reproduction, parthenogenesis, etc.), the basic principles of reproduction, both at the molecular and the organismal levels, have remained the same since the dawn of life: formation of gametes to facilitate the transfer of genetic material and epigenetic information to the next generation. Indeed, in several model organisms, orthologous genes have been identified that perform similar roles in reproductive physiology, thereby highlighting a conservation of this complex biological process.

Historically, two major obstacles have impeded the study of reproductive biology in mammals (reviewed by Staub 2001). First, germ cells in mammals develop in a microenvironment of supporting stromal cells of somatic origin that interacts with the former through autocrine/ paracrine mechanisms as well as direct cell-to-cell interactions (Matzuk et al. 2002). Devoid of this support, isolated germ cells in culture fail to survive and maintain their characteristics, making it highly difficult to study molecular interactions and pathways that are unique to these cells. The second, but related, hindrance has been the inability to develop a proper cellular context in vitro that would allow undifferentiated germ cells to differentiate into specialized gametes that retain their ability to fertilize and produce healthy offspring. Recently, interest has exploded in the field of in vitro germ cell differentiation (Lacham-Kaplan 2004, West \& Daley 2004) due to exciting findings by several investigators who have been able to generate meiosis-competent germ cells from undifferentiated embryonic stem cells (Hubner et al. 2003, Toyooka et al. 2003, Geijsen et al. 2004). Although these gametes have been shown to fertilize oocytes and produce blastocysts, no data are available yet to suggest that these can progress to produce live offspring. In addition, Feng and coworkers (2002) have generated an undifferentiated spermatogonial cell line immortalized by the ectopic expression of the catalytic component of telomerase. The cell line was also shown to differentiate in vitro to morphologically similar haploid round spermatids but the authors did not investigate whether these haploid germ cells were competent to initiate fertilization and zygotic development when injected into oocytes. So, although the future looks promising, more careful analysis of the physiological state of these in vitro-formed gametes, including the identification of parent-of-origin-specific imprints, would be critical for enhancing the utility of these techniques.

Our understanding of the molecular mechanisms of mammalian reproduction therefore has been largely dependent on loss-of-function mutagenesis in mice. Ever since researchers developed techniques to culture mouse embryonic cells in vitro (Evans \& Kaufman 1981) and 
methods were developed to inject cultured embryonic pluripotential cells into blastocysts to produce germ-line chimeras (Bradley et al. 1984), the field of mouse transgenic technology has undergone a veritable explosion. Around the same time, researchers were successfully targeting exogenous DNA into endogenous loci based on limited amounts of homology between the two DNA sequences in cultured mammalian cells (Smithies et al. 1985). Simultaneously, Thomas and colleagues (Thomas et al. 1986, Thomas \& Capecchi 1987) had developed a highly efficient method of targeted mutagenesis of cultured embryonic stem cells and other mammalian cells by using homologous recombination between endogenous genes and exogenously introduced DNA (targeting vector), a technique that was shown to be highly specific by Doetschman and coworkers (Doetschman et al. 1987, 1988). Our present-day knockout technology, a cornerstone of functional genomic studies, got its final form when these two technologies were harnessed together to generate the first targeted knockout mouse model through homologous recombination in embryonic stem cells (Koller et al. 1989).

A knockout mouse model is typically designed to produce a null mutation in the target gene and thus uncover an essential function. In dissecting gene functions, a hypomorphic mutation or the generation of an allelic series can at times be beneficial to researchers testing for genetic interactions between candidate genes. However, a null mutation is preferred in identifying non-redundant and essential functions of genes, as exemplified by the generation of approximately 300 mouse knockouts that manifest defects in reproduction (see below and online table that accompanies Matzuk \& Lamb 2002).

Among the earliest mouse knockouts generated that were found to affect different aspects of reproduction were Inha (inhibin $\alpha$ ), Lif (leukemia inhibitory factor), and estrogen receptor $\alpha$ (Matzuk et al. 1992, Stewart et al. 1992, Lubahn et al. 1993). While LIF-deficient females had defects in implantation, knockout males and females of inhibin $\alpha$ were infertile and had gonadal tumors. Female mice null for estrogen receptor $\alpha$ were infertile, and males had reduced fertility. Over the last decade, several hundred mouse knockouts have been created that affect different stages of reproduction (reviewed in Matzuk \& Lamb 2002), including primordial germ cell (PGC) formation and migration into the gonads, gonad development and sex determination, postnatal gametogenesis, sperm-egg binding and fertilization, and early embryonic development. For more comprehensive background on these topics and the mouse models that have shed light on these stages of reproductive development, readers are referred to these excellent reviews: Bendel-Stenzel et al. (1998), Matzuk \& Lamb (2002), Matzuk et al. (2002), Primakoff \& Myles (2002), Zhao \& Garbers (2002), de Rooij \& de Boer (2003), Brennan \& Capel (2004) and Park \& Jameson (2005).

In this review, we focus, in a stage-specific manner, on specific knockouts that have proved pivotal in our understanding of the biology of reproduction, with special emphasis on a few in vivo models that have clarified or refuted conflicting findings from in vitro experiments. We then briefly describe the principle of conditional mutagenesis and highlight its use in reproductive studies. Finally we discuss some of the current deficits of these technologies that have tempered the enthusiasm of researchers embracing them as their primary tools in functional genomics.

\section{Germ-line specification: what seals the fate?}

In most model organisms studied so far, the germ line is specified in embryos by a maternally derived source of egg cytoplasm referred to as the germ plasm. In mammals, however, germ-cell determination appears to be regulated within the classical developmental paradigm of cell signaling and cell adhesion.

In mice, PGCs are the founder cells of the germ line that are allocated from a pool of proximal epiblast cells at around embryonic day 7.2 (E 7.2; reviewed in Zhao \& Garbers 2002). By using mice that were deficient for bone morphogenetic protein (BMP), member $4\left(B m p 4^{-1-}\right.$ mice), Lawson and colleagues (1999) provided clear evidence that germ-cell competence is induced in a subset of proximal epiblast cells in response to BMP4 secreted from the extra-embryonic ectoderm. In $B m p 4^{-1-}$ mice PGCs were completely absent, and in Bmp4 heterozygotes the PGC number was either greatly reduced or completely absent, suggesting that the effect of BMP4 is dosedependent (Lawson et al. 1999). Deficiency of the related transforming growth factor $\beta$ (TGF $\beta$ ) superfamily members, BMP8b and BMP2, led to a very similar phenotype of reduced or absent PGCs on a mixed genetic background (Ying et al. 2000; Ying \& Zhao 2001). Interestingly, mice null for SMAD5 or SMAD1 (Chang \& Matzuk 2001, Tremblay et al. 2001), the intracellular effectors of BMP signaling, have pronounced defects in PGC formation as well. More recently, knockout mice carrying a targeted mutation in the type I BMP receptor, activin receptor-like kinase 2 (ALK2), were found to have a complete absence of PGCs, further highlighting the importance of this signaling pathway in germ-cell specification (de Sousa Lopes et al. 2004).

While these studies suggest that an intact BMP signaling system in the embryonic stages is necessary for PGC fate specification, what is not clear is whether such a signaling mechanism is actually sufficient to induce PGC fate. What are the primary targets of BMP4 and BMP8b signaling in the epiblast? Do they signal directly to the PGC precursors? Is there a master regulator of PGC fate? These are some of the questions that remain unsolved. However, a recent study, utilizing a knockout in the mouse zinc-fingercontaining transcriptional repressor PRDM1 (PR domain containing 1 , with zinc-finger domain), has uncovered an essential role for this protein in PGC specification. Embryos lacking the PRDM1 protein have a complete absence of 
PGCs while heterozygotes have a drastic reduction in PGC number (Vincent et al. 2005). Since Prdm1 transcripts are expressed in PGC precursors as early as E 7.0, this is the first transcriptional factor to be identified that plays an essential role in PGC specification. So, is PRDM1 the master regulator that seals the fate of PGC precursors into entering a germ-cell lineage? The answer to that question awaits further studies, which would address key questions regarding the sufficiency of PRDM1 in specifying a germcell fate upon non-committed epiblast cells and whether its action is cell-autonomous in these precursors.

Studying gene function through knockouts has proved highly significant in the field of reproduction not only because of the uncovering of new genes and pathways but also because these in vivo studies on many occasions served to prove or refute several models that were based on either cell-culture-based assays or on evidence from forward-genetics approaches. One instance is noteworthy: by analyzing the expression pattern of genes from solitary nascent PGCs, Saitou and colleagues (2002) proposed a mechanism for acquisition of germ-cell competence and specification in PGC precursors in the epiblast which was based on essential roles for two highly expressed and unique cDNAs (named fragilis and stella) in PGC fate determination. However, when the stella gene was knocked out in mice, there appeared to be no defects in the specification, maintenance or proliferation of PGCs (Payer et al. 2003, Bortvin et al. 2004); instead, knockout males were fertile although null females failed to sire normal numbers of offspring as the gene fulfilled an essential role in the pre-implantation development of embryos as a maternally derived factor. In this context it would be interesting to know the phenotype of mice with a null mutation in fragilis.

\section{PGC proliferation, migration and survival}

Subsequent to their specification from precursor cells, PGCs undergo several rounds of proliferation till E 13.5, around when they enter cell-cycle arrest in $\mathrm{G}_{0}$ within the male gonad or meiotic prophase I in the female gonad. In between, they migrate to the gonads by E 10.5 (Molyneaux \& Wylie 2004) after traveling through the hindgut and the dorsal mesentery in response to secreted cues from the environment.

Through knockout approaches, researchers have identified several new genes that play essential roles in some or all of these processes. Targeted disruption of a peptidylprolyl isomerase-encoding gene, Pin 1, uncovered an unexpected role for this gene in the regulation of the cell cycle and PGC proliferation. On an isogenic C57BL/6) background, mice null for Pin1 were found to have reduced PGC numbers during the mid-to-late migratory phases (E 9.5-12.5) compared with wild-type mice (Atchison et al. 2003); by analyzing BrdU labeling, this reduction seemed to be due to a delay in progression through the cell cycle rather than due to a cell-cycle arrest or enhanced apoptosis in these cells.

Specific genes regulate the survival of the migratory germ cells: the POU domain transcription factor, Oct4 (Pou5f1; Mouse Genome Informatics), is a critical determinant of pluripotency in the inner cell mass that causes embryonic death when mutated (Nichols et al. 1998, Niwa et al. 2000). To circumvent the early embryonic death and to examine the effect of deletion of Oct4 from PGCs, investigators have used TNAP Cre (tissue nonspecific alkaline phosphatase - Cre), which encodes the Cre recombinase only in the $\mathrm{PGC}$ population prior to $\mathrm{E}$ 10.5 (Kehler et al. 2004; Table 1). Surprisingly, loss of OCT4 protein from PGCs leads not to differentiation but to enhanced apoptosis in these cells prior to their colonization of the gonads.

Nanos3, a mouse homolog of the Drosophila nanos gene, represents another interesting knockout model in which the mouse homolog was found to perform an evolutionarily conserved role in flies and mammals (Forbes \& Lehmann 1998). In Nanos3 ${ }^{-1-}$ mice, PGC proliferation and/or survival during migration through the hindgut was severely disrupted, leading to sterility in both sexes. In further examples of evolutionary conservation of these

Table 1 Conditional mutants with defects in reproduction.

\begin{tabular}{|c|c|c|c|c|}
\hline Gene & Cre driver & Tissue affected & Null phenotype & References \\
\hline Oct4 (Pou5f1) & TNAP & PGC & Increased PGC apoptosis & Kehler et al. (2004) \\
\hline Dax1 (NrOb1) & CMV & Preimplantation embryo & Aberrant spermatogenesis, male infertility & Yu et al. (1998) \\
\hline Sox 9 & Sf1 & Fetal gonad & Male-female sex reversal & Chaboissier et al. (2004) \\
\hline Bmpr1a & Amhr2 & Müllerian duct & Persistent Müllerian-duct structures in males & Jamin et al. (2002) \\
\hline Sf1 (Nr5a1) & Amhr2 & $\begin{array}{l}\text { Leydig cells and } \\
\text { granulosa cells }\end{array}$ & $\begin{array}{l}\text { Semi-descended testis, impaired } \\
\text { spermatogenesis; hemorrhagic cystic ovary }\end{array}$ & Jeyasuria et al. (2004) \\
\hline $\operatorname{Ar}$ & Amh & Sertoli cells & $\begin{array}{l}\text { Increased germ-cell apoptosis, spermatogenic } \\
\text { arrest, testicular atrophy }\end{array}$ & $\begin{array}{l}\text { Chang et al. (2004), } \\
\text { De Gendt et al. (2004) }\end{array}$ \\
\hline Fst & Amhr2 & Granulosa cells & Decreased ovarian follicles, ovarian failure & Jorgez et al. (2004) \\
\hline GP130 (II6st) & TNAP & Oocytes & Defective oocyte maturation/ovulation & Molyneaux et al. (2003a) \\
\hline Pig-a (Piga) & Zp3 & Oocytes & Defective sperm-egg binding, infertility & Alfieri et al. (2003) \\
\hline Pten & TNAP & PGC & $\begin{array}{l}\text { Testicular teratoma, increased embryonic germ } \\
\text { cell proliferation }\end{array}$ & Kimura et al. (2003) \\
\hline Dnmt3a & TNAP & Spermatogonia, oocytes & Absence of de novo parental imprints, sterility & Kaneda et al. (2004) \\
\hline
\end{tabular}


mechanisms knockout mice deficient in the chemokine stromal cell-derived factor-1 (Sdf1) and its cognate receptor CXCR4 (chemokine C-X-C motif receptor 4) show defective colonization of the gonads by PGCs (Ara et al. 2003, Molyneaux et al. 2003b).

PGCs that successfully navigate to the genital ridges enter cell-cycle arrest, although at different stages in the two sexes, as mentioned above. Heterozygosity for the transcription factor zinc-finger protein 148 (Zfp148) has been shown to increase apoptosis and cause complete loss of germ cells from the male gonad at the E 13.5 stage (Takeuchi et al. 2003), an effect that is probably due to improper regulation of the p53 protein in these cells. Thus Zfp148 is one more addition to the growing list of genes that seem to affect PGC specification and maintenance in a dosage-dependent manner in mice.

\section{Sex determination}

Acquisition of reproductive competence in mammals involves the development of both germ cells and the supporting somatic cells that together constitute the gonad. The development of either the testis or the ovary from a bipotential gonad is a complex developmental process that is influenced by several transcriptional pathways. The first gene that was identified to play an essential role in determining the sex of the gonad was the Y-chromosomeencoded putative transcription factor Sry. In mice the Sry gene product has been shown to be both necessary and sufficient to impose a testis fate on the bipotential gonad (Lovell-Badge \& Robertson 1990, Koopman et al. 1991). Although a recent report described a role for SRY in pre-mRNA splicing (Ohe et al. 2002), downstream targets of this master sex-determining gene remain elusive. Our understanding of sex determination and gonadal organogenesis therefore have been dependent on targeted mutagenesis of factors that have been implicated to regulate Sry or to affect gonad formation in other model organisms or through spontaneous mutations leading to sex-reversal phenotypes in humans and mice (reviewed in Brennan \& Capel 2004). Among these, the X-linked gene encoding the orphan nuclear receptor DAX1 (NR0B1, nuclear receptor subfamily 0 , group $B$, member 1 ; Mouse Genome Informatics) was initially believed to cause $X Y$ sex reversal in mice when over-expressed in a Sry hypomorphic mutant background (Swain et al. 1998). Since overexpression of DAX1 led to the development of female reproductive structures from a bipotential gonad, albeit on a sensitized background, it was assumed that this gene was critical for ovarian development. Intriguingly, targeted deletion of Dax1, employing a conditional allele, does not lead to failure of ovarian development; on the contrary, postnatal spermatogenesis is impaired while null females are fully fertile (Yu et al. 1998). Furthermore, when the Dax $1^{+-}$females were mated to males with the hypomorphic Sry allele, all XY offspring were sex-reversed and their external and internal genitalia were completely indistinguishable from their wild-type XX siblings (Meeks et al. 2003), suggesting that this gene interacts with Sry to determine gonadal sex in mice and is required not for ovarian development but for spermatogenesis, probably through its action in Sertoli cells.

It is critical to note, however, that the role of DAX1 is highly dependent on the genetic background of the mice under investigation. A recent study by Eicher and colleagues demonstrated that although DAX1 function is essential on the C57BL/6 (B6) background for testis development in $\mathrm{XY}$ mice, it is completely dispensable on the DBA/2J background (Bouma et al. 2005). In B6 Dax1 ${ }^{-} / \mathrm{Y}$ mice, there was a failure of up-regulation of Sox9, which is another important gene in the sex-determination pathway (see below), even though Sry expression initiated normally.

The homeobox gene Sox9 is the earliest marker of preSertoli cells following Sry expression. Through the use of a conditional knockout model SOX9 has been shown to be essential for normal testis differentiation and sex-cord formation in the testis (Chaboissier et al. 2004). SOX9 regulates the differentiation of Sertoli cells and the production of male-specific markers Amh (anti-Müllerian hormone) and P450scc (cytochrome P450 side-chain cleavage), both of which are decreased in homozygous knockout mice. Indeed, this finding is a corroboration of earlier studies in which targeted disruption of the SOX9-binding site in the mouse Amh promoter caused a failure of transcription of Amh (see Table 2) that resulted in non-regression of the Müllerian duct structures in XY mice and the formation of pseudo-hermaphrodites, confirming that SOX9-mediated up-regulation of $\mathrm{AMH}$ is a critical and specific step that is

Table 2 Point mutagenesis, knockins and tissue-specific promoter ablations reveal promoter regions/specific isoforms essential for reproductive organ development and/or physiology.

\begin{tabular}{llll}
\hline Gene/regulatory element & \multicolumn{1}{c}{ Mutation } & \multicolumn{1}{c}{ Phenotype } & References \\
\hline Amh promoter & SOX9-binding site & Pseudo-hermaphrodites & Arango et al. (1999) \\
Pgr (A isoform) & Mutation in AUG & Female infertility & Mulac-Jericevic et al. (2000) \\
Wt1 (+KTS isoform) & Exon 9 splice site & XY sex reversal & Hammes et al. (2001) \\
Wt1 (-KTS isoform) & Exon 9 splice site & Gonadal agencies & Hammes et al. (2001) \\
Inhba & Inhbb knockin & Delayed fertility in males, females subfertile & Brown et al. (2000) \\
Dnmt1o & Deletion of oocyte-specific & Loss of allele-specific imprints, embryonic & Howell et al. (2001) \\
& promoter and exon 1 & lethality &
\end{tabular}


essential in the male sex-determination pathway (Arango et al. 1999). Precisely how AMH mediates regression of Müllerian duct structures in vivo has been characterized by the generation of a conditional knockout for one of the type I BMP receptors, Bmpr1a (Jamin et al. 2002); male mice lacking these receptors in mesenchymal cells of the Müllerian duct fail to respond to $\mathrm{AMH}$ and have persistent uteri and oviducts.

Two isoforms of the WT1 (Wilms' Tumor 1) protein, produced by alternative splicing, that differ in the presence or absence of 3 amino acids (KTS; the +KTS and -KTS forms) play unique roles in gonad development and sex determination. By introducing point mutations in the gene to create mutants expressing either one of the two isoforms, deficiency of the -KTS form was found to cause gonadal agenesis in both sexes whereas a loss of the + KTS form uncovered a critical role for this isoform in male sex determination as both $\mathrm{XX}$ and $\mathrm{XY}$ homozygotes developed along the female pathway (Hammes et al. 2001; Table 2). Since Sry expression was reduced in the KTS-ablated WT1 homozygotes, it can be inferred that WT1 + KTS is important for Sry-mediated XY gene program establishment in the bipotential gonad; whether this down-regulation is a direct result of WT1 + KTS loss or as a result of decreased numbers of Sry-expressing pre-Sertoli cells awaits further experiments.

Another gene involved in ovary development is Wnt4, which is required for Müllerian duct formation in both sexes prior to sex determination (Vainio et al. 1999); female mice lacking Wnt4 exhibit partial female-male sex reversal. Since Fst-null ovaries have a similar defect and since Fst expression is absent in Wnt4-null XX gonads, Fst, operating downstream of Wnt4, has been implicated in the suppression of BMP and/or activin signaling to suppress the male-specific coelomic vessel (Yao et al. 2004).

\section{Molecular control of pre-antral folliculogenesis}

Folliculogenesis in the mammalian ovary is one of the most intricately regulated developmental processes in biology. Not only does normal folliculogenesis entail the complex interplay of both long-range endocrine cues and short-range paracrine and autocrine factors, the development of viable offspring from fertilization depends, to a large extent, on the structural and functional integrity of the mature oocyte (Matzuk \& Lamb 2002, Matzuk et al. 2002). Physiologically, it is useful to visualize ovarian follicles as divided into two broad groups, each being characterized by the presence or absence of a morphological antrum (cavity). Follicles prior to the formation of an antrum are independent of the pituitary gonadotropins for growth and survival; these pre-antral follicles undergo an extensive growth phase once they have been recruited into the active pool although they remain arrested in a prolonged diplotene stage of meiosis throughout this phase. In contrast, around the period of antrum formation, oocytes regain meiotic competence and oocytes in early antral follicles depend on pituitary follicle stimulating hormone (FSH) for survival and growth.

The formation of primordial follicles in the newborn mouse ovary is preceded by the development of germ-cell clusters in the embryonic ovary in which the dividing germ cells undergo incomplete cytokinesis to remain connected to each other through intercellular bridges and their subsequent breakdown perinatally (Pepling \& Spradling 2001). The search for active players that regulate the formation of primordial follicles in mammals has resulted in the discovery of a bHLH (basic helix-loop-helix) transcription factor called FIG $\alpha$ (factor in the germ line $\alpha$; Figla) present specifically in the female germ cells. Mice carrying a targeted disruption of the Figla gene Figla $^{-/-}$) had comparable number of germ cells in their ovaries with respect to wild-type ovaries at the E 18-19 stage (Soyal et al. 2000). However, by postnatal day 1 (PD 1) the oocytes in the Figla ${ }^{-/-}$ovaries failed to grow in size and began to disappear; by PD 2 the null ovaries were completely devoid of primordial follicles. The Figla ${ }^{-1-}$ oocytes do progress through meiosis I, but fewer cells survive beyond the diplotene stage, suggesting that FIG $\alpha$ regulates the expression of survival factors/growth factors at this stage.

While Figla represents an oocyte-derived factor critical for the formation of primordial follicles, data from another mutant provide evidence that primordial follicle formation is regulated by the somatic components as well. Mutants lacking the Wnt4 gene product die shortly after birth due to defects in kidney development; however, at day 1 the mutant ovaries have a dramatic reduction in the number of meiotic-stage oocytes and most oocytes degenerate shortly thereafter (Vainio et al. 1999). A similar finding has emerged from mice with follistatin-deficient ovaries (Yao et al. 2004), highlighting the functional interactions between these two proteins (see above).

Shortly after birth a subset of primordial follicles is selected from a resting pool of quiescent follicles to undergo the follicular activation and growth. Follicular activation is characterized by oocyte growth and the transition of squamous to cuboidal granulosa cells, which signals the formation of a primary follicle followed by granulosa cell proliferation. Work from our group and others has recently identified several proteins believed to be critical at this step. A homeobox transcription factor, NOBOX, which is specific to the oocyte in the newborn ovary (Rajkovic et al. 2004), is essential in this process. In Nobox $^{-1-}$ ovaries, primordial follicles do not develop into primary follicles and beyond; instead, by PD 14, the majority of the primordial follicles are lost leading to ovarian failure and infertility. Future studies will illustrate the target genes for this transcription factor and uncover other oocyte-specific genes that play critical roles in this process.

Primordial follicles are recruited in cohorts for growth, differentiation, and maturation through a series of highly regulated processes. However, primordial follicles in 
Foxo3a $a^{-1-}$ ovaries undergo global activation so that by PD 14 the null ovaries do not have any quiescent primordial follicles but have an almost 2-fold increase in the number of primary and secondary follicles as compared with wild-type ovaries. Significantly, the null ovaries also have an almost 4-fold increase in atretic follicles and an approx. 14-fold increase in the amount of zona pellucida remnants, suggesting that the majority of the growing follicles undergo atresia following the formation of the zona pellucida by the oocyte. Not surprisingly, therefore, this sequence of global activation and atresia leads to a premature depletion of the pool of primordial follicles and secondary infertility by 15 weeks of age (Castrillon et al. 2003, Hosaka et al. 2004).

Mutations in the human forkhead transcription factor FOXL2 cause an autosomal dominant condition referred to as Blepharophimosis/ptosis/epicanthus inversus syndrome (BPES), associated with premature ovarian failure (Crisponi et al. 2001, De Baere et al. 2001). Mice with a targeted disruption in the murine ortholog (Foxl $2^{-/-}$ mice) of the human gene are infertile and provide a mechanism to explain the etiology of BPES. In Foxl $2^{-1-}$ mice granulosa cells in the mutant ovaries do not make the squamous-cuboidal transition and consequently the mutants lack any secondary follicles and are infertile (Schmidt et al. 2004). Another granulosa-cell derived factor that regulates the rate of follicle recruitment, in a subtler manner, is the anti-Müllerian hormone $(\mathrm{AMH})$, which, when secreted from the granulosa cells of secondary follicles, acts in a paracrine fashion within the follicle to inhibit the recruitment of primordial follicles. In $\mathrm{Amh}^{-1-}$ females there is a derepression of the follicular activation process causing mutant ovaries to be depleted of primordial follicles earlier than in wild-type ovaries (Durlinger et al. 1999).

Growth differentiation factor 9 (Gdf9) is an oocytederived mitogenic paracrine factor that plays a critical role in folliculogenesis by regulating the somatic components of the follicle. Gdf9 encodes for a member of the TGF $\beta$ superfamily of secreted proteins that play important roles in cell proliferation and differentiation in mammals (Chang et al. 2002). Members of this family, such as GDF9, BMP15, AMH, and activins, exquisitely regulate early stages of folliculogenesis. In mice, a null mutation in Gdf9 causes complete infertility in female mice (Dong et al. 1996). Histopathological examination of null ovaries demonstrate a total lack of normal appearing secondary follicles indicating that GDF9 secreted from oocytes acts upon the granulosa cell population to augment the proliferation/differentiation of these follicular supporting cells. Thus, GDF9 is essential for the primary-to-secondary follicle transition in mice. The oocyte that has already entered the growth phase following activation continues to grow in these follicles (Carabatsos et al. 1998); however, devoid of the close support from the granulosa cell mass there is atresia of both the oocyte and eventually the somatic cells.
Another member of the TGF $\beta$ superfamily of proteins that appears to play an important role in pre-antral stages of folliculogenesis is BMP15. BMP15 is secreted from oocytes and regulates the proliferation and differentiation of the granulosa cell population. Analysis of a null mutation in Bmp15 generated in our laboratory revealed that Bmp15 ${ }^{-/-}$mice are subfertile and display defects in ovulation and fertilization (Yan et al. 2001). However, studies in sheep have shown that BMP15 may also play important roles at the primary to secondary follicle transition (Galloway et al. 2000) or, alternatively, the mutant BMP15 may antagonize the functions of GDF9 (Liao et al. 2004).

\section{Spermatogenesis}

In adult mammals, spermatogenesis is one of the most highly productive biological processes; one study (Johnson et al. 1992) done on human testis specimens obtained at autopsy estimated that the daily sperm production ranges between 3.5 and 7.5 million sperm/g of testis parenchyma. This tremendous capacity to produce spermatozoa throughout the life of an individual rests solely on the selfrenewing capacity of spermatogonial stem cells, which constitute a small group of pluripotent cells present in the mature testis. Concomitant with the identification of molecular markers that identify the spermatogonial stem-cell pool (Kubota et al. 2004) has come new knowledge on the regulation, survival and proliferation of these rare populations of adult stem cells in vivo through knockout studies. Here we briefly review some of these models that have illustrated the utility of the targeted knockout approach.

Among the first mutations that were identified to have a defect in spermatogonia were the $W$ and $S /$ mutations (Russell et al. 1979) that affect the Kit receptor, which is present on differentiating spermatogonia and its ligand, the Stem cell factor, which is produced in the Sertoli cells. However, mutations in the Kit signaling system affect only the differentiated spermatogonia as the receptor Kit is not expressed on earlier spermatogonial populations (Donovan \& de Miguel 2001). Recently, glial cell-derived neurotrophic factor (GDNF), another Sertoli cell-derived factor distantly related to the TGF $\beta$ family of growth factors, was shown, in a dose-dependent manner, to control the cell-fate decision of undifferentiated spermatogonia; reduced levels of GDNF caused spermatogonial differentiation and depletion of the stem-cell pool while high levels in vivo caused a differentiation block and increase in the numbers of spermatogonia (Meng et al. 2000). Germ-cell factors that play equally important roles in the proliferation of undifferentiated spermatogonia have also been identified through mouse knockouts; prominent has been the identification of a zinc-finger-containing transcriptional repressor, $\mathrm{Plzf}$, that is essential for stem-cell self-renewal in the adult testis (Buaas et al. 2004, Costoya et al. 2004). Although the precise genes that are regulated 
by this transcription factor are not yet known, future studies utilizing transcriptome analysis of spermatogonia similar to the approach used by Costoya and colleagues (2004) should lead to further insights into the molecular mechanisms of germ-line stem-cell biology.

Knockouts have been created that identify essential genes at almost all steps of spermatogenesis (reviewed in Matzuk \& Lamb 2002, de Rooij \& de Boer 2003); literally hundreds of mutant mice have been characterized with arrest at various stages such as a spermatogonial differentiation block, pachytene stage meiotic arrest, and defects in spermiogenesis and sperm function.

Several genes that are expressed in post-meiotic cells have been found to be essential for spermiogenesis in a dose-sensitive manner. Notable among these are mutations in the genes encoding protamines 1 and 2 ( $P r m 1$ and Prm2), Kelch-like 10 (K/h/10) and sperm antigen 16 (Spag16), haploinsufficiency of which are incompatible with male fertility (Cho et al. 2001, Yan et al. 2004, Zhang et al. 2004). Male mice that are high-percentage chimeras of these genes are unable to transmit the mutant alleles through the germ line due to either severe morphological defects (as in the Prm1 or Prm2 mice) or severe reduction of sperm count and defects in sperm morphology and function (KIh/10 or Spag16). During spermiogenesis, chromatin packaging in the sperm head requires the replacement of histones by the transition proteins and protamines. Similar to protamines, deficiency of both transition proteins 1 and 2 also leads to severe defects in sperm morphology and infertility (Zhao et al. 2004), thereby highlighting the importance of proper chromatin remodeling during spermatogenesis.

Defects in sperm motility also lead to infertility; analysis of knockouts of CatSper1 (Ren et al. 2001) and CatSper2 (Quill et al. 2003), which are cationic channels present on the sperm membrane, a sperm-specific isoform of a glycolytic enzyme, Gapdhs (Miki et al. 2004), and of structural components of the axoneme (Spag6, Tekt2) have revealed interesting models of asthenozoospermia (Sapiro et al. 2002, Tanaka et al. 2004) that lead to infertility in male mice. Finally, knockouts have uncovered genes that play essential functions in the final step of sperm function, sperm-egg binding (reviewed in Evans 2001, Primakoff \& Myles 2002). The plethora of single-knockout models that impair spermatogenesis at so many discrete steps is in addition to numerous models that cause a hitherto undefined or non-specific block in spermatogenesis and as a whole serve to illustrate both the complexity of this process and the huge number of potential targets for development of contraceptives in humans.

\section{Endocrine, paracrine and autocrine regulation of gametogenesis}

Germ cells are dependent on the somatic cells of the gonad (Sertoli and Leydig cells in the testis; granulosa and theca cells in the ovary) for development, which are in turn regulated by gonadotropins secreted by the pituitary, namely FSH and luteinizing hormone (LH). Deficiency of the pituitary gonadotropins leads to hypogonadism in both sexes, as in the hpg (hypogonadal) mouse, which carries a naturally occurring deletion in the gonadotropin-releasing hormone $(\mathrm{GnRH})$ gene and consequently are infertile with reduction in the size of the gonads and accessory sex organs as well as a block in gametogenesis (Mason et al. 1986). Since hpg mice lack both LH and FSH, the relative contributions of each of these gonadotropin hormones to the phenotypic spectrum was not clear until our group and others created knockouts of four different genes in mice: Fshb (FSH $\beta$ subunit), Fshr (FSH receptor), Lhb (LH $\beta$ subunit) and $L h r(\mathrm{LH}$ receptor). Analyzing the effects of these single knockouts revealed that FSH and LH had non-redundant roles in both sexes. In males, loss of FSH signaling resulted in smaller testis size, reduced spermatogenesis, and impaired sperm motility although the males were fertile (Kumar et al. 1997, Dierich et al. 1998). In contrast, females deficient for a functional FSH signaling pathway are sterile with thin uteri and hypoplastic ovaries due to a block in folliculogenesis prior to antrum formation (Kumar et al. 1997). An intact LH signaling pathway, however, is essential in both sexes as both males and females deficient for either $\mathrm{LH} \beta$ subunit or its cognate receptor develop hypogonadism and infertility (Lei et al. 2001, Zhang et al. 2001, Ma et al. 2004). Furthermore, folliculogenesis is blocked in LH-deficient ovaries at an early antral stage, suggesting that the progression from secondary to early antral follicle stage is dependent on FSH while $\mathrm{LH}$ is required for further development. Similarly in males, spermatogenesis is blocked at the round spermatid stage, revealing an absolute requirement for only LH in further maturation of the haploid gametic cells.

Sex hormones (estrogen and progesterone in females, testosterone in males) have been long believed to play essential roles in the development, differentiation and proper function of female and male reproductive systems. Targeted knockouts of their respective receptors have revealed precisely how these steroid hormones function and have uncovered hitherto unsuspected roles for estrogen signaling in males and testosterone in females. Estrogen acts through two nuclear hormone receptors, ER $\alpha$ and ER $\beta$; whereas deletion of ER $\beta$ leads to subfertility (Krege et al. 1998) due to defects in granulosa cell development (Dupont et al. 2000), disruption of ER $\alpha$ results in female infertility due to a complete lack of ovulation with the null ovaries displaying hemorrhagic cysts (Lubahn et al. 1993, Dupont et al. 2000). Interestingly, ER $\alpha$-knockout males are infertile as well due to a defect in fluid reabsorption in the epididymis that leads to degeneration of seminiferous tubules and disruption of spermatogenesis (Eddy et al. 1996, Hess et al. 1997), thereby identifying a male-specific role for estrogen. Progesterone, which also acts through two receptor isoforms (PR-A and PR-B), was believed to be important for the establishment and 
maintenance of the pregnant state; however, deletion of the progesterone receptor in females led to infertility due to defects in ovulation with associated uterine inflammation and disruption of mammary gland morphogenesis (Lydon et al. 1995). Identifying which of these effects were mediated by the two receptor isoforms required some subtle manipulations because both isoforms were generated from the same gene from alternative promoters and translation initiation sites. In elegant experiments, MulacJericevic and colleagues (Mulac-Jericevic et al. 2000, 2003) mutated the two AUG initiation codons in embryonic stem cells and generated PR-A and PR-B knockouts (Table 2). Analysis of these mutants revealed essential roles for PR-A in ovulation and uterine physiology while PR-B was important for mammary gland development.

Studies from the spontaneous $t f m$ (testicular feminized) mutant and from androgen receptor-knockout mice (Yeh et al. 2002) have shown androgen signaling to be essential for the descent of testes, development of male accessory sex organs, and spermatogenesis beyond the pachytene spermatocyte stage. Recently, generation of Sertoli cell-specific knockout of the androgen receptor have clarified the roles of testosterone signaling by demarcating androgen signaling in these cells as essential for spermatogenesis but not for non-gonadal functions of testosterone (Chang et al. 2004, De Gendt et al. 2004). Interestingly, signaling through the androgen receptor has also been found to have important roles in female fertility as null females show longer estrous cycles and reduced fertility (Hu et al. 2004).

Studies from our group and several others have also discovered the essential roles played by multiple TGF $\beta$ family members in reproduction (reviewed by Pangas \& Matzuk 2004, Jorgez et al. 2005; see Fig. 1). Among these, the Inha mouse model revealed unexpectedly important roles for the protein in gonadal cell-cycle regulation as null animals developed gonadal tumors of granulosa cell/Sertoli cell origin (Matzuk et al. 1992). As identified by our group and others, also important in reproduction are the activin signaling components; activin receptor type II mutants develop testicular hypoplasia and activin $\beta B$ subunit mutants have defective parturition (Vassalli et al. 1994, Matzuk et al. 1995). In order to analyze the functional interaction between activin $\beta A$ and activin $\beta B$, our group also created a knockin allele of $\beta B$ into the $\beta A$ locus (Table 2). The knockin rescued the neonatal lethality of the $\beta A-k n o c k o u t$ mice, thus allowing dissection of the reproductive phenotype (Brown et al. 2000). While male knockin mice had delayed fertility, female mice had severely reduced fertility, thus highlighting the important roles played by activin $\beta \mathrm{A}$ in mammalian reproduction. Also significant is the follistatin conditional knockout model in which the activin/BMP/GDF antagonist follistatin is deleted only in the granulosa cells of the ovary. Female mice with a granulosa cell-specific deletion of follistatin have severely reduced fertility due to reduced numbers of ovarian follicles and defects in ovulation and fertilization

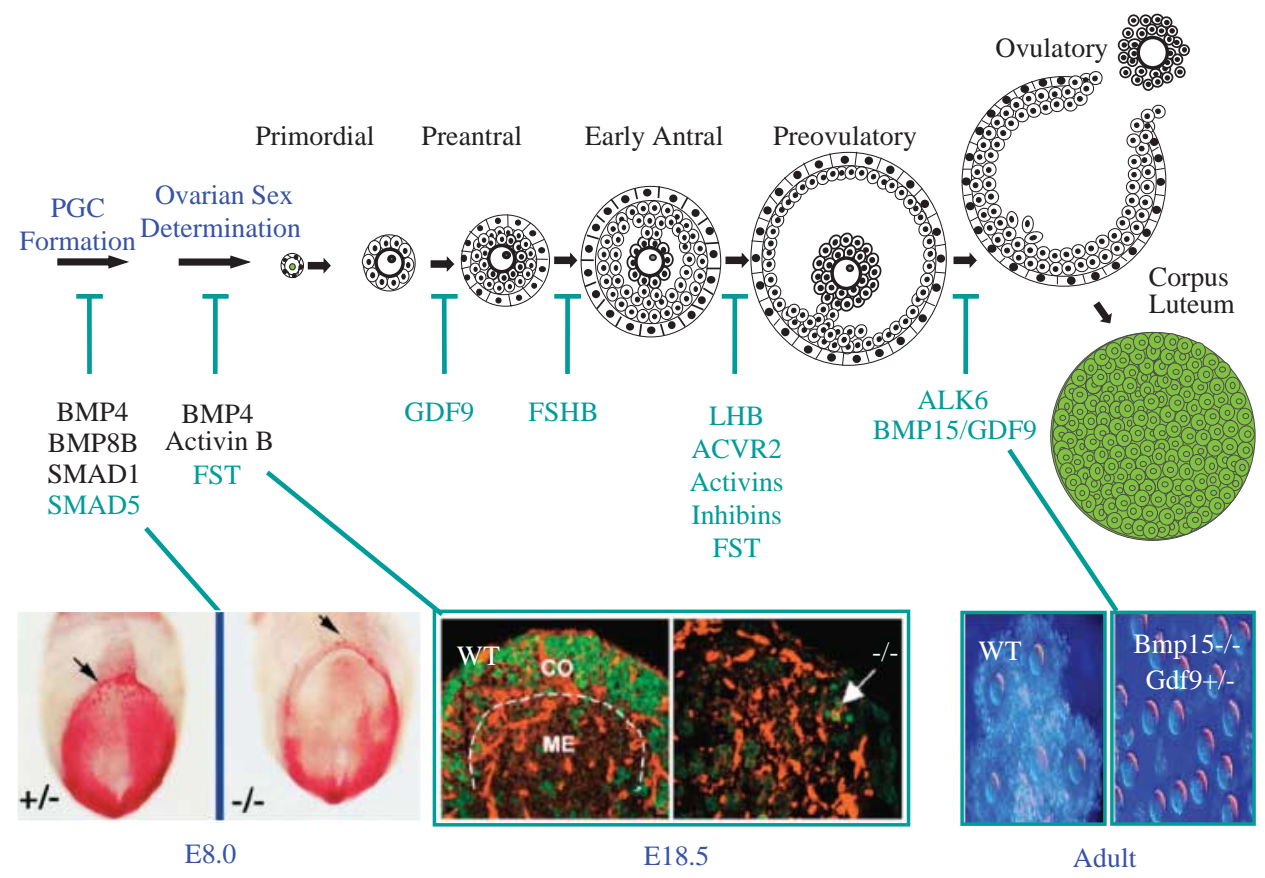

Figure 1 TGF $\beta$ superfamily signaling in germ-cell formation, sex determination, and ovarian folliculogenesis. Null mutations in several members of this family result in an arrest in the development of the reproductive system. Whereas Smad5 ${ }^{-1-}$ embryos lack PGCs at E 8.0 (Chang \& Matzuk 2001), $\mathrm{Fst}^{-1-}$ mice have a loss of germ cells at E 18.5 ((Yao et al. 2004). Oocytes from Bmp $15^{-1-} / \mathrm{Gdfg}^{+/-}$double mutants display defective cumulus-cell adherence to the oocytes (Yan et al. 2001). WT, wild type; ME, medulla; CO, cortex; ACVR2, activin receptor type 2. 
(Jorgez et al. 2004). These and other models (reviewed by Chang et al. 2002) have identified an enormous number of proteins belonging to the TGF $\beta$ superfamily with essential roles in reproduction.

\section{Early embryo: the maternal effect}

In the early embryonic period prior to zygotic genome activation, maternally supplied proteins play critical roles in pre-implantation development. The first such maternally derived factor identified was Mater (Nalp5). Embryos lacking maternal NALP5 protein arrested at the two-cell stage and degenerated, thereby suggesting an essential role of maternal NALP5 protein in embryonic development (Tong et al. 2000). Maternally supplied oocyte-specific isoform of the DNA methyltransferase 1 (Dnmt1o) was also found to be essential for maintenance of methylation at imprinted loci in embryos; heterozygous embryos of null females died in utero due to alteration of allele-specific expression from imprinted loci (Howell et al. 2001; Table 2). Methyltransferases that are implicated in initiation of methylation at imprinted loci (Dnmt3 I and Dnmt3a) have also been demonstrated to be essential maternally supplied proteins for embryonic viability (Bourc'his et al. 2001, Kaneda et al. 2004). Recently our group and others have added to the list of maternal effect genes in mice. First, female mice null for an oocyte-specific gene Zar1 (zygote arrest 1) were found to be infertile due to a failure of progression of fertilized embryos from the one- to twocell stage (Wu et al. 2003); in the arrested embryos the parental genomes remain separated and there is a marked reduction in the synthesis of the transcription-requiring complex. Thus Zar1 seems to act at an earlier time-point than Mater in embryonic development. Next, a mouse homolog of Xenopus nucleoplasmin (nucleoplasmin 2, Npm2) was identified to be critical in the process as well. Embryos from Npm2-null females had defects in nuclei and nucleolar organization specifically evident in the loss of heterochromatin from these organelles (Burns et al. 2003). Although, some embryos are able to proceed through the two-cell stage and diminished numbers of offspring are born from null females, most embryos show reduced cleavage to the two-cell stage. Another recent maternal-effect factor to be identified is Stella or Dppa3 (developmental pluripotency-associated 3). Embryos from Dppa3 ${ }^{-1-}$ females progress to the four-cell stage but are defective in further cleavage and in pre-implantation development (Payer et al. 2003, Bortvin et al. 2004). Future experiments utilizing in silico approaches to identifying early-embryo-enriched genes would provide more candidate genes that might play important roles during this phase of embryonic development.

\section{Conditional mutagenesis}

Although a knockout mouse is a valuable resource to analyze the effects of a null mutation in a tissue of interest, in a large number of cases the study of the phenotype is precluded by a more widespread effect caused by the mutation (for example, embryonic or perinatal lethality of homozygotes). Also, distinguishing between the cell-autonomous and cell-non-autonomous nature of action of a gene of interest is not possible in a ubiquitous knockout. Researchers have long recognized this drawback of the traditional knockout approach and have sought to develop technologies that would allow ablation of a gene function in a specific tissue and at a specific time: this is the rationale behind the conditional mutagenesis approach. Over the years refinement and innovation have led to a whole set of new tools with which conditional knockouts are achieved in vivo at present (see Lewandoski 2001 for a detailed review); here we discuss the advantages and pitfalls of the use of the binary Cre-loxP technology in the generation of conditional mutants within the context of reproduction. For a list of available Cre lines, go to www.mshri.on.ca/nagy/Cre-pub.html and see Table 1; for a list of available floxed alleles, go to www.mshri.on.ca/nagy/floxed.html.

The binary Cre-loxP method is so designed that the bacteriophage recombinase Cre is driven by a tissue- or stage-specific promoter in a restricted spatio-temporal manner; the deletion of gene function in that tissue is then dependent on the Cre recombinase to bind to its cognate recognition sequences (IoxP) sites and effect a DNA recombination event between any two of such loxP sites, which can lead to deletion, inversion and other genomic rearrangements based on the position and orientation of such sites. The gene (or more commonly, the gene region) to be deleted is flanked by loxP ('floxed') sites in a targeting event similar to a conventional knockout; floxed mice are then bred with mice expressing Cre under the regulation of a promoter of choice to obtain tissue-specific knockouts in the offspring. Using this method several conditional knockouts have been generated that display reproductive defects (see Table 1); indeed, some of them were created after conventional knockouts resulted in embryonic or postnatal lethality (Oct4 and Fst).

One apparent deficit of this technology in reproduction is the paucity of available Cre- driver lines that are specifically expressed in reproductive tissues of interest. Another problem relates to the fact that our restricted knowledge of gene-regulatory elements results in use of promoter regions that prove to be 'leaky', meaning that they drive Cre expression and consequently gene deletion outside of their specific spatio-temporal zone (for example the Sf1Cre line), thus defeating the very purpose of creating a conditional knockout. The last problem, and not a trivial one, is the issue of the efficiency of Cre-mediated recombination. Cre lines often express the recombinase at levels that are not sufficient to achieve complete recombination between $\operatorname{lox} P$ sites, thus resulting in the generation of a hypomorph. Attention has been focused on producing 
more efficient deleter Cre lines (Shimshek et al. 2002) but we are still some distance from achieving mastery over this elegant but at times difficult technology. Nevertheless, with the intensive efforts of various groups and the advent of newer technologies, for example inducible Cre lines, the Flp-Frt system, it is conceivable that in the future, instead of one cure for all ills, the field will witness the use of a multitude of technologies each best tailored in a particular situation to deliver the proper result: that of generation of a null mutation in the tissue of interest.

\section{In the future}

Worldwide, $15 \%$ of couples are unable to conceive within 1 year of starting unprotected intercourse (Matzuk \& Lamb 2002). Although fertility defects may be the secondary manifestation of systemic illnesses (endocrinopathies, neurological disorders, anatomic malformations), which may or may not be treatable, often the defect is primary to the reproductive system and requires specialized evaluation of urologists and/or gynecologists and fertility specialists for possible treatment. However, even with advanced clinical tools for diagnosis of reproductive defects, about a quarter of clinical infertility cases are diagnosed as idiopathic (Matzuk \& Lamb 2002). Since the identification of the genetic bases of a complex disorder such as infertility cannot be done through traditional genetic approaches of pedigree analysis and linkage studies, our understanding of the genetics of reproduction in humans has remained minimal and is limited to a few documented examples such as the discovery of Y-chromosome microdeletions in azoospermic men or the findings of cystic fibrosis transmembrane conductance regulator (CFTR) mutations in patients with congenital bilateral absence of the vas deferens. This raises the possibility that some of these 'idiopathic' cases are likely due to as-yet unidentified genetic anomalies.

In this review we have illustrated some examples of how knockouts in mice have greatly enhanced our understanding of this complex biological process. This is not meant to be a comprehensive survey of all knockouts with reproductive defects but rather an illustrative essay of the utility of the knockout approach towards understanding a process. Challenges remain plenty in both our understanding of the process and in the use of this technology itself, but the emergence of exciting technologies and projects such as RNA interference in mammals (reviewed in Mittal 2004), the MICER project for genome-wide large-scale insertional mutagenesis from indexed targeting vectors (Adams et al. 2004), and the recent conceptualization of a whole-genome knockout mouse project, or KOMP, by an international collaboration (Austin et al. 2004) will broaden the scope and increase the enthusiasm of researchers in the power of knockouts and knockdowns in evaluating the roles of additional proteins in the reproductive axis in vivo.

\section{Acknowledgements}

The authors declare that there is no conflict of interest that would prejudice the impartiality of this scientific work.

\section{References}

Adams DJ, Biggs PJ, Cox T, Davies R, van der Weyden L, Jonkers J et al. 2004 Mutagenic insertion and chromosome engineering resource (MICER). Nature Genetics 36 867-871.

Alfieri JA, Martin AD, Takeda J, Kondoh G, Myles DG \& Primakoff P 2003 Infertility in female mice with an oocyte-specific knockout of GPI-anchored proteins. Journal of Cell Science 116 2149-2155.

Ara T, Nakamura Y, Egawa T, Sugiyama T, Abe K, Kishimoto T et al. 2003 Impaired colonization of the gonads by primordial germ cells in mice lacking a chemokine, stromal cell-derived factor-1 (SDF-1). PNAS 100 5319-5323.

Arango NA, Lovell-Badge R \& Behringer RR 1999 Targeted mutagenesis of the endogenous mouse Mis gene promoter: in vivo definition of genetic pathways of vertebrate sexual development. Cell 99 409-419.

Atchison FW, Capel B \& Means AR 2003 Pin1 regulates the timing of mammalian primordial germ cell proliferation. Development $\mathbf{1 3 0}$ 3579-3586.

Austin CP, Battey JF, Bradley A, Bucan M, Capecchi M, Collins FS et al. 2004 The knockout mouse project. Nature Genetics 36 921-924.

Bendel-Stenzel M, Anderson R, Heasman J \& Wylie C 1998 The origin and migration of primordial germ cells in the mouse. Seminars in Cell Development and Biology 9 393-400.

Bortvin A, Goodheart M, Liao M \& Page DC 2004 Dppa3 / Pgc7 / stella is a maternal factor and is not required for germ cell specification in mice. BMC Developments in Biology 42.

Bouma GJ, Albrecht KH, Washburn LL, Recknagel AK, Churchill GA \& Eicher EM 2005 Gonadal sex reversal in mutant Dax1 XY mice: a failure to upregulate Sox9 in pre-Sertoli cells. Development 132 3045-3054.

Bourc'his D, Xu GL, Lin CS, Bollman B \& Bestor TH 2001 Dnmt3L and the establishment of maternal genomic imprints. Science 294 2536-2539.

Bradley A, Evans M, Kaufman MH \& Robertson E 1984 Formation of germ-line chimaeras from embryo-derived teratocarcinoma cell lines. Nature 309 255-256.

Brennan J \& Capel B 2004 One tissue, two fates: molecular genetic events that underlie testis versus ovary development. Nature Reviews in Genetics 5 509-521.

Brown CW, Houston-Hawkins DE, Woodruff TK \& Matzuk MM 2000 Insertion of Inhbb into the Inhba locus rescues the Inhba-null phenotype and reveals new activin functions. Nature Genetics 25 453-457.

Buaas FW, Kirsh AL, Sharma M, McLean DJ, Morris JL, Griswold MD et al. 2004 Plzf is required in adult male germ cells for stem cell self-renewal. Nature Genetics 36 647-652.

Burns KH, Viveiros MM, Ren Y, Wang P, DeMayo FJ, Frail DE et al. 2003 Roles of NPM2 in chromatin and nucleolar organization in oocytes and embryos. Science 300 633-636.

Carabatsos MJ, Elvin J, Matzuk MM \& Albertini DF 1998 Characterization of oocyte and follicle development in growth differentiation factor-9-deficient mice. Developmental Biology 204 373-384.

Castrillon DH, Miao L, Kollipara R, Horner JW \& DePinho RA 2003 Suppression of ovarian follicle activation in mice by the transcription factor Foxo3a. Science 301 215-218.

Chaboissier MC, Kobayashi A, Vidal VI, Lutzkendorf S, van de Kant HJ, Wegner M et al. 2004 Functional analysis of Sox8 and Sox9 during sex determination in the mouse. Development 131 1891-1901.

Chang C, Chen YT, Yeh SD, Xu Q, Wang RS, Guillou F et al. 2004 Infertility with defective spermatogenesis and hypotestosteronemia 
in male mice lacking the androgen receptor in Sertoli cells. PNAS 101 6876-6881.

Chang H \& Matzuk MM 2001 Smad5 is required for mouse primordial germ cell development. Mechanisms in Development 104 61-67.

Chang H, Brown CW \& Matzuk MM 2002 Genetic analysis of the mammalian transforming growth factor-beta superfamily. Endocrine Reviews 23 787-823.

Cho C, Willis WD, Goulding EH, Jung-Ha H, Choi YC, Hecht NB \& Eddy EM 2001 Haploinsufficiency of protamine-1 or -2 causes infertility in mice. Nature Genetics 28 82-86.

Costoya JA, Hobbs RM, Barna M, Cattoretti G, Manova K, Sukhwani M et al. 2004 Essential role of Plzf in maintenance of spermatogonial stem cells. Nature Genetics 36 653-659.

Crisponi L, Deiana M, Loi A, Chiappe F, Uda M, Amati P et al. 2001 The putative forkhead transcription factor FOXL2 is mutated in blepharophimosis/ptosis/epicanthus inversus syndrome. Nature Genetics 27 159-166.

De Baere E, Dixon MJ, Small KW, Jabs EW, Leroy BP, Devriendt K et al. 2001 Spectrum of FOXL2 gene mutations in blepharophimosis-ptosis-epicanthus inversus (BPES) families demonstrates a genotype-phenotype correlation. Human Molecular Genetics 10 1591-1600.

De Gendt K, Swinnen JV, Saunders PT, Schoonjans L, Dewerchin M, Devos A et al. 2004 A Sertoli cell-selective knockout of the androgen receptor causes spermatogenic arrest in meiosis. PNAS 101 $1327-1332$.

de Rooij DG \& de Boer P 2003 Specific arrests of spermatogenesis in genetically modified and mutant mice. Cytogenetics \& Genome Research $103267-276$

de Sousa Lopes SM, Roelen BA, Monteiro RM, Emmens R, Lin HY, Li E et al. 2004 BMP signaling mediated by ALK2 in the visceral endoderm is necessary for the generation of primordial germ cells in the mouse embryo. Genes \& Development 18 1838-1849.

Dierich A, Sairam MR, Monaco L, Fimia GM, Gansmuller A, LeMeur M \& Sassone-Corsi P 1998 Impairing follicle-stimulating hormone (FSH) signaling in vivo: targeted disruption of the FSH receptor leads to aberrant gametogenesis and hormonal imbalance. PNAS $9513612-13617$.

Doetschman T, Gregg RG, Maeda N, Hooper ML, Melton DW, Thompson S \& Smithies O 1987 Targetted correction of a mutant HPRT gene in mouse embryonic stem cells. Nature 330 576-578.

Doetschman T, Maeda N \& Smithies O 1988 Targeted mutation of the Hprt gene in mouse embryonic stem cells. PNAS 85 8583-8587.

Dong J, Albertini DF, Nishimori K, Kumar TR, Lu N \& Matzuk MM 1996 Growth differentiation factor-9 is required during early ovarian folliculogenesis. Nature 383 531-535.

Donovan PJ \& de Miguel MP 2001 The role of the C-Kit/Kit ligand axis in mammalian gametogenesis. In Transgenics in Endocrinology, pp 147-163. MM Matzuk, CW Brown, TR Kumar, Eds. Totowa: Humana Press.

Dupont S, Krust A, Gansmuller A, Dierich A, Chambon P \& Mark M 2000 Effect of single and compound knockouts of estrogen receptors alpha (ERalpha) and beta (ERbeta) on mouse reproductive phenotypes. Development 127 4277-4291.

Durlinger AL, Kramer P, Karels B, de Jong FH, Uilenbroek JT, Grootegoed JA \& Themmen AP 1999 Control of primordial follicle recruitment by anti-Mullerian hormone in the mouse ovary. Endocrinology 140 5789-5796.

Eddy EM, Washburn TF, Bunch DO, Goulding EH, Gladen BC, Lubahn DB \& Korach KS 1996 Targeted disruption of the estrogen receptor gene in male mice causes alteration of spermatogenesis and infertility. Endocrinology 137 4796-4805.

Evans JP 2001 Fertilin beta and other ADAMs as integrin ligands: insights into cell adhesion and fertilization. Bioessays 23 628-639.

Evans MJ \& Kaufman MH 1981 Establishment in culture of pluripotential cells from mouse embryos. Nature 292 154-156.
Feng LX, Chen Y, Dettin L, Pera RA, Herr JC, Goldberg E \& Dym M 2002 Generation and in vitro differentiation of a spermatogonial cell line. Science 297 392-395.

Forbes A \& Lehmann R 1998 Nanos and Pumilio have critical roles in the development and function of Drosophila germline stem cells. Development 125 679-690.

Galloway SM, McNatty KP, Cambridge LM, Laitinen MP, Juengel JL, Jokiranta TS et al. 2000 Mutations in an oocyte-derived growth factor gene (BMP15) cause increased ovulation rate and infertility in a dosage-sensitive manner. Nature Genetics 25 279-283.

Geijsen N, Horoschak M, Kim K, Gribnau J, Eggan K \& Daley GQ 2004 Derivation of embryonic germ cells and male gametes from embryonic stem cells. Nature 427 148-154.

Hammes A, Guo JK, Lutsch G, Leheste JR, Landrock D, Ziegler U et al. 2001 Two splice variants of the Wilms' tumor 1 gene have distinct functions during sex determination and nephron formation. Cell 106 319-329.

Hess RA, Bunick D, Lee KH, Bahr J, Taylor JA, Korach KS \& Lubahn DB 1997 A role for oestrogens in the male reproductive system. Nature 390 509-512.

Hosaka T, Biggs WH 3rd, Tieu D, Boyer AD, Varki NM, Cavenee WK \& Arden KC 2004 Disruption of forkhead transcription factor (FOXO) family members in mice reveals their functional diversification. PNAS $1012975-2980$.

Howell CY, Bestor TH, Ding F, Latham KE, Mertineit C, Trasler JM \& Chaillet JR 2001 Genomic imprinting disrupted by a maternal effect mutation in the Dnmt1 gene. Cell 104 829-838.

Hu YC, Wang PH, Yeh S, Wang RS, Xie C, Xu Q et al. 2004 Subfertility and defective folliculogenesis in female mice lacking androgen receptor. PNAS 101 11209-11214.

Hubner K, Fuhrmann G, Christenson LK, Kehler J, Reinbold R, De La Fuente R et al. 2003 Derivation of oocytes from mouse embryonic stem cells. Science $\mathbf{3 0 0} 1251-1256$

Jamin SP, Arango NA, Mishina Y, Hanks MC \& Behringer RR 2002 Requirement of Bmpr1a for Mullerian duct regression during male sexual development. Nature Genetics 32 408-410.

Jeyasuria P, Ikeda Y, Jamin SP, Zhao L, De Rooij DG, Themmen AP et al. 2004 Cell-specific knockout of steroidogenic factor 1 reveals its essential roles in gonadal function. Molecular Endocrinology 18 $1610-1619$

Johnson L, Chaturvedi PK \& Williams JD 1992 Missing generations of spermatocytes and spermatids in seminiferous epithelium contribute to low efficiency of spermatogenesis in humans. Biology of Reproduction 47 1091-1098.

Jorgez CJ, Klysik M, Jamin SP, Behringer RR \& Matzuk MM 2004 Granulosa cell-specific inactivation of follistatin causes female fertility defects. Molecular Endocrinology 18 953-967.

Jorgez CJ, Lin YN \& Matzuk MM 2005 Genetic manipulations to study reproduction. Molecular \& Cellular Endocrinology 234 127-135.

Kaneda M, Okano M, Hata K, Sado T, Tsujimoto N, Li E \& Sasaki H 2004 Essential role for de novo DNA methyltransferase Dnmt3a in paternal and maternal imprinting. Nature 429 900-903.

Kehler J, Tolkunova E, Koschorz B, Pesce M, Gentile L, Boiani M et al. 2004 Oct4 is required for primordial germ cell survival. EMBO Reports 5 1078-1083.

Kimura T, Suzuki A, Fujita Y, Yomogida K, Lomeli $\mathrm{H}$, Asada $\mathrm{N}$ et al. 2003 Conditional loss of PTEN leads to testicular teratoma and enhances embryonic germ cell production. Development 130 $1691-1700$.

Koller BH, Hagemann LJ, Doetschman T, Hagaman JR, Huang S, Williams PJ et al. 1989 Germ-line transmission of a planned alteration made in a hypoxanthine phosphoribosyltransferase gene by homologous recombination in embryonic stem cells. PNAS $\mathbf{8 6}$ 8927-8931.

Koopman P, Gubbay J, Vivian N, Goodfellow P \& Lovell-Badge R 1991 Male development of chromosomally female mice transgenic for Sry. Nature 351 117-121. 
Krege JH, Hodgin JB, Couse JF, Enmark E, Warner M, Mahler JF et al. 1998 Generation and reproductive phenotypes of mice lacking estrogen receptor beta. PNAS 95 15677-15682.

Kubota H, Avarbock MR \& Brinster RL 2004 Growth factors essential for self-renewal and expansion of mouse spermatogonial stem cells. PNAS 101 16489-16494.

Kumar TR, Wang Y, Lu N \& Matzuk MM 1997 Follicle stimulating hormone is required for ovarian follicle maturation but not male fertility. Nature Genetics 15 201-204.

Lacham-Kaplan O 2004 In vivo and in vitro differentiation of male germ cells in the mouse. Reproduction 128 147-152.

Lawson KA, Dunn NR, Roelen BA, Zeinstra LM, Davis AM, Wright CV et al. 1999 Bmp4 is required for the generation of primordial germ cells in the mouse embryo. Genes Development 13 424-436.

Lei ZM, Mishra S, Zou W, Xu B, Foltz M, Li X \& Rao CV 2001 Targeted disruption of luteinizing hormone/human chorionic gonadotropin receptor gene. Molecular Endocrinology 15 184-200.

Lewandoski M 2001 Conditional control of gene expression in the mouse. Nature Reviews in Genetics 2 743-755.

Liao WX, Moore RK \& Shimasaki S 2004 Functional and molecular characterization of naturally occurring mutations in the oocyte-secreted factors bone morphogenetic protein-15 and growth and differentiation factor-9. Journal of Biological Chemistry 279 $17391-17396$.

Lovell-Badge R \& Robertson E 1990 XY female mice resulting from a heritable mutation in the primary testis-determining gene. $T d y$. Development 109 635-646.

Lubahn DB, Moyer JS, Golding TS, Couse JF, Korach KS \& Smithies O 1993 Alteration of reproductive function but not prenatal sexual development after insertional disruption of the mouse estrogen receptor gene. PNAS $9011162-11166$.

Lydon JP, DeMayo FJ, Funk CR, Mani SK, Hughes AR, Montgomery CA Jr et al. 1995 Mice lacking progesterone receptor exhibit pleiotropic reproductive abnormalities. Genes \& Development 9 $2266-2278$.

Ma X, Dong Y, Matzuk MM \& Kumar TR 2004 Targeted disruption of luteinizing hormone beta-subunit leads to hypogonadism, defects in gonadal steroidogenesis, and infertility. PNAS 101 17294-17299.

Mason AJ, Hayflick JS, Zoeller RT, Young WS 3rd, Phillips HS, Nikolics K \& Seeburg PH 1986 A deletion truncating the gonadotropin-releasing hormone gene is responsible for hypogonadism in the hpg mouse. Science 234 1366-1371.

Matzuk MM \& Lamb DJ 2002 Genetic dissection of mammalian fertility pathways. Nature Cell Biology 4 Suppl S41-S49.

Matzuk MM, Finegold MJ, Su JG, Hsueh AJ \& Bradley A 1992 Alpha-inhibin is a tumour-suppressor gene with gonadal specificity in mice. Nature $360313-319$.

Matzuk MM, Kumar TR \& Bradley A 1995 Different phenotypes for mice deficient in either activins or activin receptor type II. Nature 374 356-360.

Matzuk MM, Burns KH, Viveiros MM \& Eppig J 2002 Intercellular communication in the mammalian ovary: oocytes carry the conversation. Science $2962178-2180$.

Meeks JJ, Weiss J \& Jameson JL 2003 Dax1 is required for testis determination. Nature Genetics 34 32-33.

Meng X, Lindahl M, Hyvonen ME, Parvinen M, de Rooij DG, Hess MW et al. 2000 Regulation of cell fate decision of undifferentiated spermatogonia by GDNF. Science 287 1489-1493.

Miki K, Qu W, Goulding EH, Willis WD, Bunch DO, Strader LF et al. 2004 Glyceraldehyde 3-phosphate dehydrogenase-S, a spermspecific glycolytic enzyme, is required for sperm motility and male fertility. PNAS 101 16501-16506.

Mittal V 2004 Improving the efficiency of RNA interference in mammals. Nature Reviews in Genetics 5 355-365.

Molyneaux K \& Wylie C 2004 Primordial germ cell migration. International Journal of Developmental Biology 48 537-544.

Molyneaux KA, Schaible K \& Wylie C 2003a GP130, the shared receptor for the LIF/IL6 cytokine family in the mouse, is not required for early germ cell differentiation, but is required cell-autonomously in oocytes for ovulation. Development 130 4287-4294.

Molyneaux KA, Zinszner H, Kunwar PS, Schaible K, Stebler J, Sunshine MJ et al. 2003b The chemokine SDF1/CXCL12 and its receptor CXCR4 regulate mouse germ cell migration and survival. Development 130 4279-4286.

Mulac-Jericevic B, Mullinax RA, DeMayo FJ, Lydon JP \& Conneely OM 2000 Subgroup of reproductive functions of progesterone mediated by progesterone receptor-B isoform. Science $\mathbf{2 8 9}$ $1751-1754$.

Mulac-Jericevic B, Lydon JP, DeMayo FJ \& Conneely OM 2003 Defective mammary gland morphogenesis in mice lacking the progesterone receptor B isoform. PNAS 100 9744-9749.

Nichols J, Zevnik B, Anastassiadis K, Niwa H, Klewe-Nebenius D, Chambers I et al. 1998 Formation of pluripotent stem cells in the mammalian embryo depends on the POU transcription factor Oct4. Cell 95 379-391.

Niwa H, Miyazaki J \& Smith AG 2000 Quantitative expression of Oct-3/4 defines differentiation, dedifferentiation or self-renewal of ES cells. Nature Genetics 24 372-376.

Ohe K, Lalli E \& Sassone-Corsi P 2002 A direct role of SRY and SOX proteins in pre-mRNA splicing. PNAS 99 1146-1151.

Pangas SA \& Matzuk MM 2004 Genetic models for transforming growth factor beta superfamily signaling in ovarian follicle development. Molecular \& Cellular Endocrinology 225 83-91.

Park SY \& Jameson JL 2005 Minireview: transcriptional regulation of gonadal development and differentiation. Endocrinology $\mathbf{1 4 6}$ 1035-1042.

Payer B, Saitou M, Barton SC, Thresher R, Dixon JP, Zahn D et al. 2003 Stella is a maternal effect gene required for normal early development in mice. Current Biology 13 2110-2117.

Pepling ME \& Spradling AC 2001 Mouse ovarian germ cell cysts undergo programmed breakdown to form primordial follicles. Developmental Biology 234 339-351.

Primakoff P \& Myles DG 2002 Penetration, adhesion, and fusion in mammalian sperm-egg interaction. Science $2962183-2185$.

Quill TA, Sugden SA, Rossi KL, Doolittle LK, Hammer RE \& Garbers DL 2003 Hyperactivated sperm motility driven by CatSper2 is required for fertilization. PNAS 100 14869-14874.

Rajkovic A, Pangas SA, Ballow D, Suzumori N \& Matzuk MM 2004 NOBOX deficiency disrupts early folliculogenesis and oocytespecific gene expression. Science 305 1157-1159.

Ren D, Navarro B, Perez G, Jackson AC, Hsu S, Shi Q et al. 2001 A sperm ion channel required for sperm motility and male fertility. Nature 413 603-609.

Russell LB, Russell WL \& Kelly EM 1979 Analysis of the albinolocus region of the mouse. I. Origin and viability. Genetics 91 127-139.

Saitou M, Barton SC \& Surani MA 2002 A molecular programme for the specification of germ cell fate in mice. Nature 418 293-300.

Sapiro R, Kostetskii I, Olds-Clarke P, Gerton GL, Radice GL \& Strauss IJ 2002 Male infertility, impaired sperm motility, and hydrocephalus in mice deficient in sperm-associated antigen 6. Molecular \& Cellular Biology 22 6298-6305.

Schmidt D, Ovitt CE, Anlag K, Fehsenfeld S, Gredsted L, Treier AC \& Treier M 2004 The murine winged-helix transcription factor Foxl2 is required for granulosa cell differentiation and ovary maintenance. Development 131 933-942.

Shimshek DR, Kim J, Hubner MR, Spergel DJ, Buchholz F, Casanova E et al. 2002 Codon-improved Cre recombinase (iCre) expression in the mouse. Genesis 32 19-26.

Smithies O, Gregg RG, Boggs SS, Koralewski MA \& Kucherlapati RS 1985 Insertion of DNA sequences into the human chromosomal beta-globin locus by homologous recombination. Nature 317 230-234.

Soyal SM, Amleh A \& Dean J 2000 FIGalpha, a germ cell-specific transcription factor required for ovarian follicle formation. Development 127 4645-4654. 
Staub C 2001 A century of research on mammalian male germ cell meiotic differentiation in vitro. Journal of Andrology 22 911-926.

Stewart CL, Kaspar P, Brunet LJ, Bhatt H, Gadi I, Kontgen F \& Abbondanzo SJ 1992 Blastocyst implantation depends on maternal expression of leukaemia inhibitory factor. Nature 359 76-79.

Swain A, Narvaez V, Burgoyne P, Camerino G \& Lovell-Badge R 1998 Dax1 antagonizes Sry action in mammalian sex determination. Nature $391761-767$.

Takeuchi A, Mishina Y, Miyaishi O, Kojima E, Hasegawa T \& Isobe K 2003 Heterozygosity with respect to Zfp148 causes complete loss of fetal germ cells during mouse embryogenesis. Nature Genetics $33172-176$

Tanaka H, Iguchi N, Toyama $\mathrm{Y}$, Kitamura K, Takahashi T, Kaseda K et al. 2004 Mice deficient in the axonemal protein Tektin-t exhibit male infertility and immotile-cilium syndrome due to impaired inner arm dynein function. Molecular \& Cellular Biology 24 7958-7964.

Thomas KR \& Capecchi MR 1987 Site-directed mutagenesis by gene targeting in mouse embryo-derived stem cells. Cell 51 503-512.

Thomas KR, Folger KR \& Capecchi MR 1986 High frequency targeting of genes to specific sites in the mammalian genome. Cell $\mathbf{4 4}$ 419-428.

Tong ZB, Gold L, Pfeifer KE, Dorward H, Lee E, Bondy CA et al. 2000 Mater, a maternal effect gene required for early embryonic development in mice. Nature Genetics 26 267-268.

Toyooka Y, Tsunekawa N, Akasu R \& Noce T 2003 Embryonic stem cells can form germ cells in vitro. PNAS 100 11457-11462.

Tremblay KD, Dunn NR \& Robertson EJ 2001 Mouse embryos lacking Smad1 signals display defects in extra-embryonic tissues and germ cell formation. Development 128 3609-3621.

Vainio S, Heikkila M, Kispert A, Chin N \& McMahon AP 1999 Female development in mammals is regulated by Wnt-4 signalling. Nature 397 405-409.

Vassalli A, Matzuk MM, Gardner HA, Lee KF \& Jaenisch R 1994 Activin/inhibin beta B subunit gene disruption leads to defects in eyelid development and female reproduction. Genes \& Development 8 414-427.

Vincent SD, Dunn NR, Sciammas R, Shapiro-Shalef M, Davis MM, Calame K et al. 2005 The zinc finger transcriptional repressor Blimp1/Prdm1 is dispensable for early axis formation but is required for specification of primordial germ cells in the mouse. Development 132 1315-1325.

West JA \& Daley GQ 2004 In vitro gametogenesis from embryonic stem cells. Current Opinions in Cell Biology 16 688-692.
Wu X, Viveiros MM, Eppig JJ, Bai Y, Fitzpatrick SL \& Matzuk MM 2003 Zygote arrest 1 (Zar1) is a novel maternal-effect gene critical for the oocyte-to-embryo transition. Nature Genetics 33 187-191.

Yan C, Wang P, DeMayo J, DeMayo FJ, Elvin JA, Carino C et al. 2001 Synergistic roles of bone morphogenetic protein 15 and growth differentiation factor 9 in ovarian function. Molecular Endocrinology 15 854-866.

Yan W, Ma L, Burns KH \& Matzuk MM 2004 Haploinsufficiency of kelch-like protein homolog 10 causes infertility in male mice. PNAS $1017793-7798$.

Yao HH, Matzuk MM, Jorgez CJ, Menke DB, Page DC, Swain A \& Capel B 2004 Follistatin operates downstream of Wnt4 in mammalian ovary organogenesis. Developmental Dynamics 230 210-215.

Yeh S, Tsai MY, Xu Q, Mu XM, Lardy H, Huang KE et al. 2002 Generation and characterization of androgen receptor knockout (ARKO) mice: an in vivo model for the study of androgen functions in selective tissues. PNAS 99 13498-13503.

Ying Y \& Zhao GQ 2001 Cooperation of endoderm-derived BMP2 and extraembryonic ectoderm-derived BMP4 in primordial germ cell generation in the mouse. Develomental Biology 232 484-492.

Ying Y, Liu XM, Marble A, Lawson KA \& Zhao GQ 2000 Requirement of Bmp8b for the generation of primordial germ cells in the mouse. Molecular Endocrinology 14 1053-1063.

Yu RN, Ito M, Saunders TL, Camper SA \& Jameson JL 1998 Role of Ahch in gonadal development and gametogenesis. Nature Genetics $20353-357$.

Zhang FP, Poutanen M, Wilbertz J \& Huhtaniemi I 2001 Normal prenatal but arrested postnatal sexual development of luteinizing hormone receptor knockout (LuRKO) mice. Molecular Endocrinology $15172-183$.

Zhang Z, Kostetskii I, Moss SB, Jones BH, Ho C, Wang H et al. 2004 Haploinsufficiency for the murine orthologue of Chlamydomonas PF20 disrupts spermatogenesis. PNAS 101 12946-12951.

Zhao GQ \& Garbers DL 2002 Male germ cell specification and differentiation. Developmental Cell 2 537-547.

Zhao M, Shirley CR, Hayashi S, Marcon L, Mohapatra B, Suganuma $\mathbf{R}$ et al. 2004 Transition nuclear proteins are required for normal chromatin condensation and functional sperm development. Genesis 38 200-213.

Received 12 July 2005

Accepted 12 September 2005 